\title{
DOCUMENTOS INÉDITOS PARA LA HISTORIA DE MAGALLANES
}

\author{
PUERTO YARTOU, TIERRA DEL FUEGO (1929)
}

\author{
Introducción y notas \\ Samuel García Oteiza ${ }^{a}$
}

En 1908 Alberto Baeriswyl Pittet (18791957) inició en el sur de Tierra del Fuego el aserradero "Puerto Yartou", emplazado a orillas del canal Whiteside y en el interior de la concesión otorgada en 1890 a la Sociedad Explotadora de Tierra del Fuego (S.E.T.F). Este emprendimiento se convirtió en el primer complejo industrial maderero de la sección chilena del territorio insular fueguino ${ }^{1}$ y uno de los de mayor producción a nivel regional. En 1930 la población que residía en este asentamiento alcanzó las 110 personas (70 hombres, 40 mujeres), cifra que duplicaba a la población de los otros aserraderos de la isla 2 . A comienzos de la década de 1940 y a causa de la "crisis maderera" que afectó a la región de Magallanes, su capacidad de producción decayó significativamente provocando el término gradual y definitivo de su actividad a gran escala (Martinic, 2009 [1982]).

El documento que desclasificamos en esta entrega esta fechado el 25 de abril de 1929 y corresponde a una tasación de todas las construcciones existentes en Puerto Yartou incluyendo sus dimensiones, materialidades, destino de las edificaciones (almacenes, baños, bodegas, casas, cocinas, galpones, muelles, etc.). Este registro, a modo de inventario, se realizó cumpliendo con lo señalado en el artículo $\mathrm{N}^{\circ} 8$ del decreto supremo $\mathrm{N}^{\circ} 740$ del 17 de noviembre de 1926, por el cual se entregó en arrendamiento a A. Baeriswyl una superficie de 10.000 hectáreas en la localidad de Puerto Yartou (Fig. 1). Según lo indicado se debía realizar la estimación económica de las mejoras existentes, cifra por la cual el arrendatario debía rendir una fianza para responder a su conservación. En aquel contexto, Agustín Ferrada Leiva (jefe de la oficina de la "Propiedad Austral" de Magallanes) se trasladó en abril de 1929 a Puerto Yartou para realizar la tasación indicada. Obtenida la valoración y rendida la fianza se entregó nuevamente el arriendo de las 10.000 hectáreas a Baeriswyl en cumplimiento al decreto supremo No 4694 del 29 de octubre de 19293.

En diciembre de 1930 la S.E.T.F. devolvió al Fisco 106.160 hectáreas correspondientes a la sección de la estancia "Cameron" 4 , formando parte de esta cabida estaban las 10.000 hectáreas arrendadas por Alberto Baeriswyl (Fig. 2). Además de Baeriswyl, los campos devueltos por la S.E.T.F y colindantes a Puerto Yartou eran ocupados desde

a Arquitecto. Investigador del Centro de Estudios del Hombre Austral, Instituto de la Patagonia, Universidad de Magallanes. samuelgarciaoteiza@gmail.com

1 Luego se fundaron simultáneamente "Puerto Arturo" (1918), "Elenita" (1918), "La Paciencia" (1918), "Bahía Blanca" (1918), "Yendegaia" (1930), "Caleta María" (1942).

2 "La Paciencia", 50 personas (37 hombres, 13 mujeres), "Puerto Arturo", 59 personas (48 hombres, 11 mujeres).
Datos obtenidos del censo de 1930.

Según las disposiciones de la ley 4.547 sobre el arrendamiento y colonización de las tierras fiscales de Magallanes.

Conforme al plano $\mathrm{N}^{\circ} 3$ a que se refieren el decreto Supremo No 3.686 del 24 de julio de 1929. 


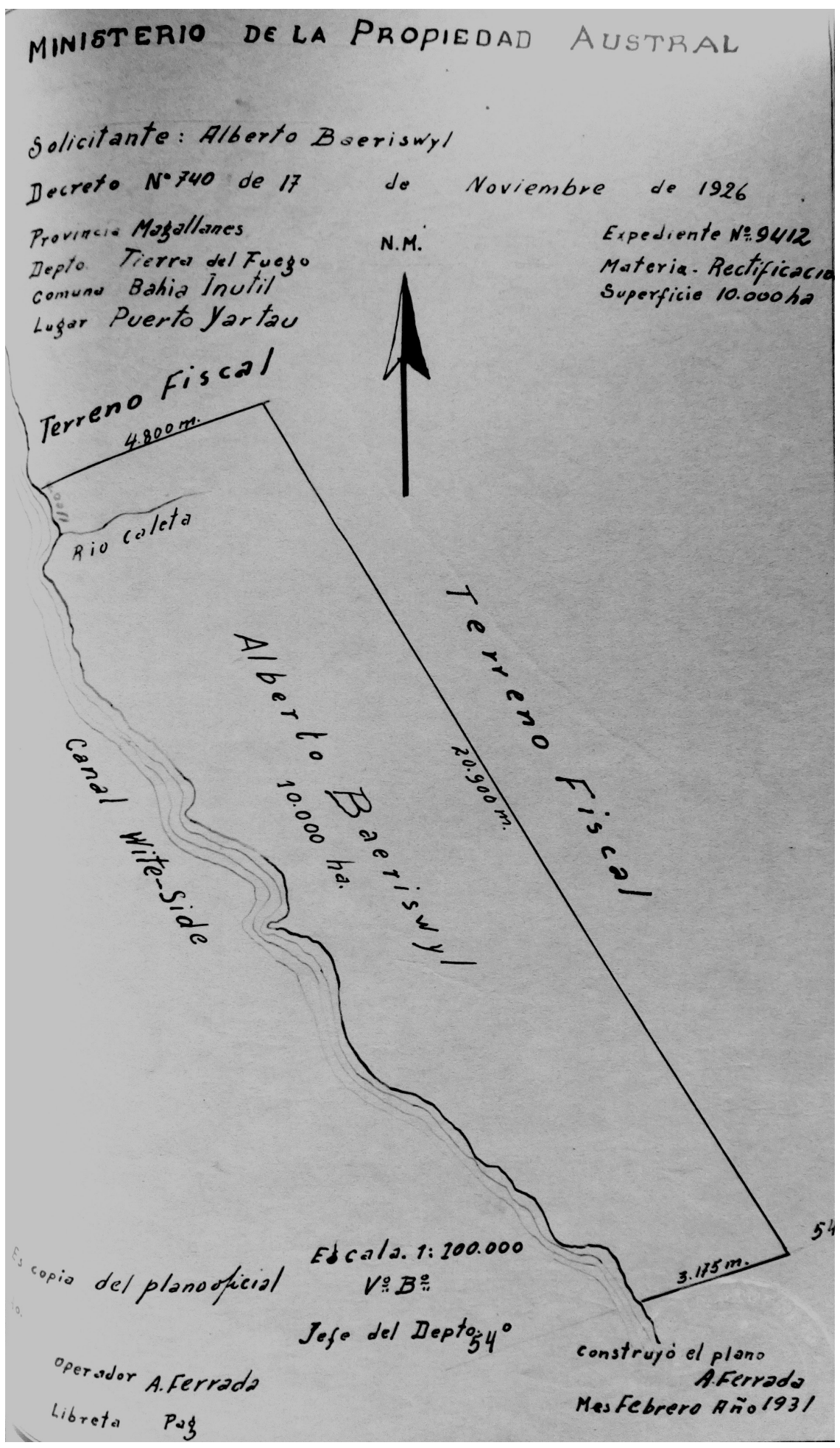

Fig. 1. Concesión de terreno de A. Baeriswyl en Puerto Yartou. Decreto supremo $N^{\circ} 740$ del 17 de noviembre de 1926. Plano elaborado por Agustín Ferrada, febrero 1931. 
1929 por Pedro Mancilla en el sector río Caleta y por Diego Ahern, desde mediados de 1930, en las inmediaciones del río Cóndor ${ }^{5}$. Cuando la oficina de la "Propiedad Austral" de Magallanes recibió oficialmente la entrega de los terrenos por parte de la S.E.T.F., Agustín Ferrada se trasladó nuevamente a Puerto Yartou el 6 de febrero de 1931 para realizar la entrega en forma personal de los terrenos arrendados por Alberto Baeriswyl $y$ atender las solicitudes de remate de los lotes que ocupaban Pedro Mancilla y Diego Ahern 6 . Además aprovechó la visita para realizar el levantamiento planimétrico, rectificación y definición de los lotes mencionados $^{7}$ (Fig. 1).

Los aserraderos que operaron en el sur de Tierra del Fuego durante la primera mitad del siglo XX ("Puerto Yartou", "Puerto Arturo", "Elenita", "La Paciencia", "Caleta María", "Bahía Blanca", "Yendegaia") carecen de una cobertura documental histórica detallada (escrita y gráfica). En este sentido el informe de Agustín Ferrada es un excelente registro que permite dimensionar la magnitud física del asentamiento industrial maderero "Puerto Yartou" y de la industria maderera magallánica en general.

Actualmente quedan algunos vestigios de equipos industriales y mínimas construcciones en pie que conformaron el antiguo aserradero "Puerto Yartou". En el año 2009 y con el objetivo de resguardar y difundir el valor patrimonial de este sitio histórico se creó la fundación "Suiza en Puerto Yartou". Una de sus primeras iniciativas fue la restauración, iniciada el 2010, de la original casa administración del aserradero y que hoy funciona como casa-museo Alberto Baeriswyl. Otra iniciativa interesante impulsada por esta fundación fue la reconstrucción planimétrica del emplazamiento de las edificaciones del complejo

5 En los campos devueltos por la S.E.T.F existían las siguientes mejoras: realizadas por la misma S.E.T.F; 36 kilómetros de alambrado (avaluado en \$39.000). Pedro Mancilla había construido: dos casas con techo de zinc y forro de madera, un galpón y corrales de palo a pique (avaluados en \$5.100). Diego Ahern, una casa palo a pique, dos corrales y dos kilómetros de cercos de barones (avaluados en $\$ 2.800$ ).

6 El lote propuesto para Pedro Mancilla era de 9.790 ha. y para Diego Ahern de 9.067 ha.

7 Para el caso del lote arrendado a Baeriswyl los límites quedaron definidos de la siguiente forma: NORTE, una maderero. Trabajo realizado, a partir de trabajos de campo y revisión detallada de fotografías históricas, por el arquitecto Nicolás Recabarren Traub y publicado en la memoria anual 2013 de la fundación "Suiza en Puerto Yartou".

Cabe señalar que el informe que transcribimos a continuación se complementa perfectamente con el plano de emplazamiento mencionado, asî también con una cantidad importante de fotografías históricas que han sido recopiladas en los últimos años por la fundación "Suiza en Puerto Yartou" (Fig. 3).

\section{- PUERTO YARTOU 1929 -}

Alberto Baeriswyl, tasación de mejoras

de lote 10.00 ha. arrendadas

en Tierra del Fuego

$N^{\circ} 136$

Magallanes, Abril 25 de 1929

\section{Señor Director General:}

Para dar cumplimiento al Art. $8^{\circ}$ del Decreto Supremo $N^{\circ} 740$ de 17 de Noviembre de 1926, por el cual se da en arrendamiento a don Alberto Baeriswyl, un lote de 10.000 hectáreas, ubicado en la Isla Grande de Tierra del Fuego, me trasladé al terreno para efectuar la tasación de las mejoras, por las que el interesado deberá rendir una fianza para responder a su conservación, tasación que acompaño en pliego por separado.

\section{Saluda a Ud. atentamente Agustin Ferrada}

\section{Al señor Director General del Departamento} de Tierras y Colonización. Santiago

recta que parte a 1.100 metros de la desembocadura del río Caleta en el mar medidos por la costa del canal Whiteside, tiene un rumbo de $N$. 72 $30^{\circ}$ y un largo de 4.800 metros; ORIENTE, una recta que forma un ángulo de $100^{\circ}$ con la anterior de un largo de 20.900 metros; SUR, el paralelo $54^{\circ}$ desde el estremo sur del deslinde Oriente hasta la costa del canal Whiteside con 3.175 metros de largo; y PONIENTE, la costa del canal Whiteside entre los deslindes sur y norte. Oficio 117. Magallanes 16 de febrero de 1931. Ministerio de la Propiedad Austral. Servicio Regional de Magallanes. 

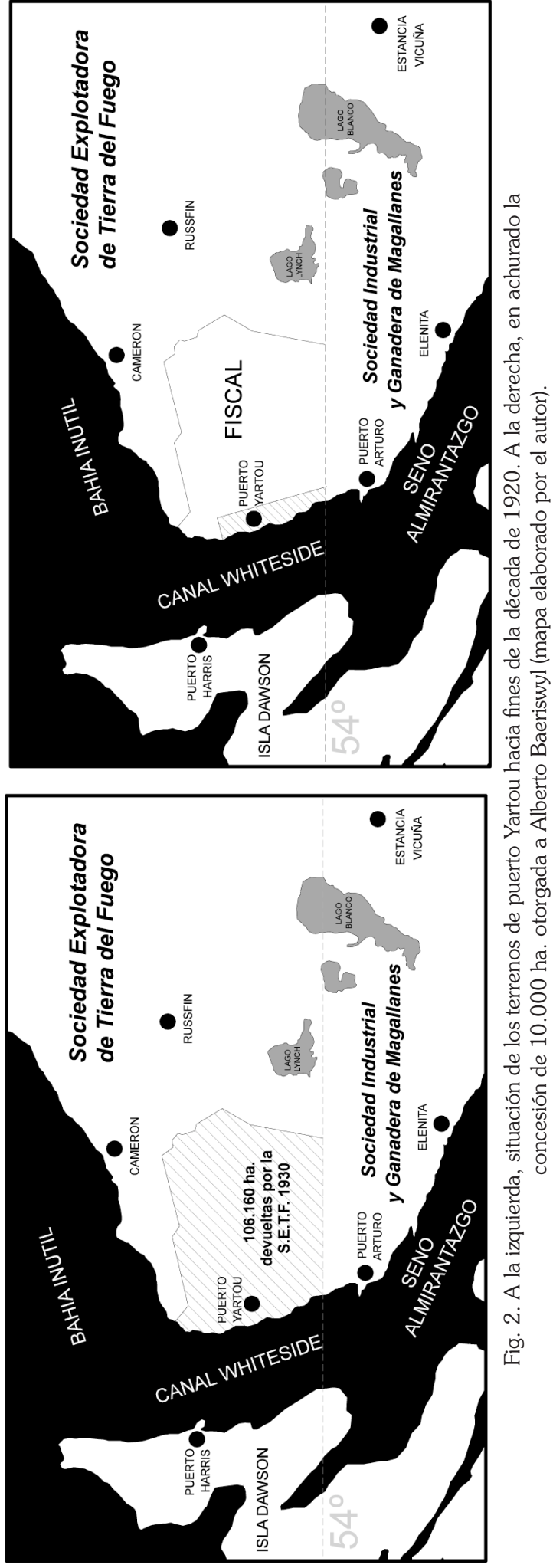

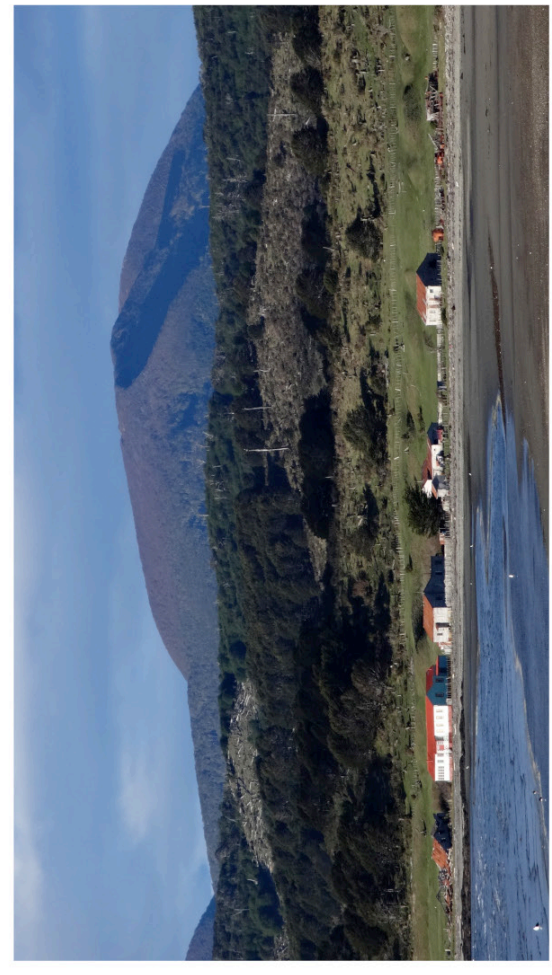

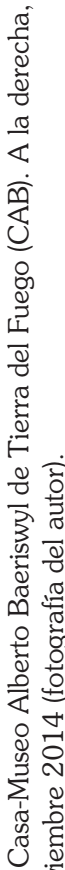

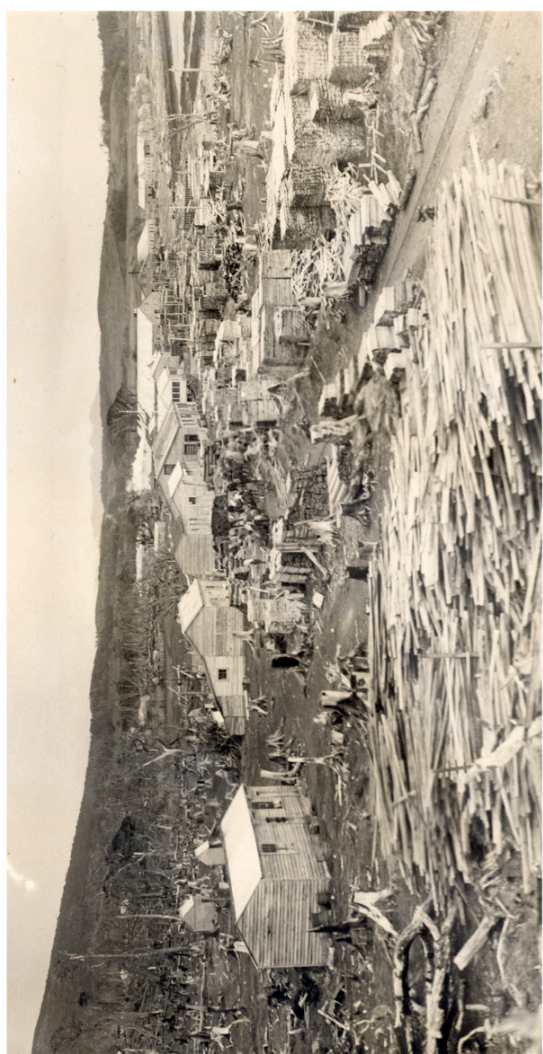


Tasación de las mejoras existentes en el lote de 10.000 hectáreas arrendadas por don Alberto Baeriswyl, en Tierra del Fuego según decreto supremo $N^{\circ} 740$ de 17 de noviembre de 1926.

\section{PUERTO YARTOU}

-1 Casa habitación de $27 \times 7$ metros con galerías; techo de zinc; forro exterior de madera; pisos, cielo raso y forros interiores de listones machihembrados...20.000

-1 Casa para trabajadores, de 25x9 metros, con dos piezas; techo y forro exteriores de tabla tinglada; forros interiores de tabla machihembrados...8.000

-Pesebrera de 15x9,5 metros; techo fierro acanalado, en mal estado, forro exterior de tabla tinglada, piso de tierra...1.500

-1 Casa inquilina de 7,30x7,30 metros; techo y forro exterior de tabla tinglada; pisos y forros interiores de listones machihembrados...1.200

-1 Casa de 11x6 metros; techo zinc; forro exterior tabla tinglada; piso y forros interiores listones machihembrados...1.600

-1 Bodega de 17x7,30 metros; techo de zinc; forros exteriores tabla tinglada, e interiores listones machihembrados...6.000

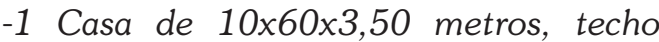
forro exterior tabla tinglada; forros interiores de listones machihembrados...2.500

-1 Casa de 9x70x7,40; techo de zinc $y$ forros interiores de listones machihembrados...3.500

-1 media agua (del muelle) de 70x5,30 metros; techo de tablas; piso de tierra...3.000

8 Esta edificación correspondía a la casa administración del aserradero. Recientemente ha sido restaurada $y$
-1 Galpón (muelle viejo) de 27×9,20 metros; techo y forros exteriores de tablas...1.100

-1 Cocina y Comedor para peones, de 20x10,20 metros; techo y forro exterior de tabla tinglada; piso y forros interiores de listones machihembrados...7.000

-1 Casa de 9x8 metros; techo de zinc nuevo; cuatro piezas; forros interiores de listones machihembrados de papel...3.500

-1 Casa de 12x7,60 metros; techo zinc en mal estado; cuatro piezas; forros exteriores tabla tinglado; forros interiores listones machihembrados...2.500

-1 Casa para escuela de 7,20x6,70 metros; techo y forros exteriores de tabla tinglada; forro interiores listones machihembrados...1.300

-1 Casa de 9,40x4 metros; techo de zinc; forros exteriores de tabla tinglada; forros interiores listones machihembrados...1.500

-1 Casa de 10,60×3,50 metros; techo tablas; forros interiores de listones machihembrados...1700

-1 Edificio destinado a Oficina y Almacenes, de 29x14 metros; techo de zinc; forros de tabla tinglada, en el exterior $y$ de listones machihembrados, en el interior...10.000

-1 Galpón de Esquila de 15x4,70 metros; techo de zinc, con sus corrales...4.000

-1 Casa de 12x10 metros; techo de zinc $y$ forros interiores de listones machihembrados...6.000

-1 Casa de 8,50x13 metros; techo de zinc; forros exteriores de tabla

funciona como casa museo Alberto Baeriswyl (CAB), www.cab-patagonia.cl 
tinglada; forros interiores de listones machihembrados...5.500

-1 Galpón de 16x55 metros; techo de zinc; forros de tablas...20.000

-1 Galpón en regular estado, de 30×18 metros; techo de zinc; forro exterior de tablas...12.000

-1 Galpón, en regular estado, de 29×20 metros; techo de zinc...10.000

-1 Galpón de 27x18 metros; techo de zinc; forro de tablas...18.000

-1 Casa de 10x40x10 metros; techo de zinc; forro exterior tablas; forro interior listones...1.000

-4 Media aguas, cada una $\$ 200 \ldots 800$

-1 casa de 9x10 metros; techo de zinc; forros interiores de tablas paradas...500

-2 casa de 10x6 metros; forros de tablas cada una $\$ 350 \ldots 700$

-1 Casa de 8x11 metros; techo de zinc; piso y forros interiores de listones machihembrados...800

-1 Casa de 28x11,60 metros; en regular estado; techo de zinc; forros interiores de listones machihembrados...5.000

-1 Baño con secadero y corrales; y un galpón de $18 \times 6$ metros, en mal estado; con techo y forros de tablas viejas...2.500

-23 Casas de inquilinos de dos piezas cada una; techo y forros exteriores de tablas y forros interiores de listones machihembrados, a $\$ 600$ c/u...13.800

-1 Muelle de 95x5,25 metros; con 90 pilotes de caños de fierro de cuatro pulgadas y 36 pilotes de madera de 12x12; y defensa del mismo muelle 16 pilotes de fierro de cuatro pulgadas y 22 de madera en...40.000 [Fig. 4]

-38.000 Metros de alambrado a $\$ 1$. cada uno...38.000

-40.000 Metros Cerco de varones a $\$ 0,50$ cada uno...20.000

Mejoras en Puerto Yartou, en total...\$274.500

\section{MEJORAS EN CALETA}

-1 Casa de 13x12,30 metros; techo de zinc; forro exterior de tablas tingladas; forros interiores y piso de tablas...3.000

\section{MEJORAS EN PUERTO ARENAS}

-1 Casa de 9,30×9,20 metros; techo de zinc; forros interiores de listones machihembrados...2.000

-1 Galponcito de tablas...400

\section{MEJORAS EN RIO CONDOR}

-1 Galponcito viejo de 39x77 metros..(se incendió)...800

-1 Casa de 7,40x6,30 metros, con techo de zinc...1.100

-1 Galpón de esquila de 20,70x7 metros, techo de zinc...3.000

-1 Baño y corrales anexos...3.500

TOTAL DE MEJORAS EXISTENTES EN EL LOTE ARRENDADO POR DON

ALBERTO BAERISWYL...288.300

Asciende la presente tasación a la cantidad de DOSCIENTOS OCHENTA Y OCHO MIL TRESCIENTOS PESOS $\mathrm{m} / \mathrm{cte}$ [moneda corriente]

Magallanes, Abril 25 de 1929 Agustín Ferrada 


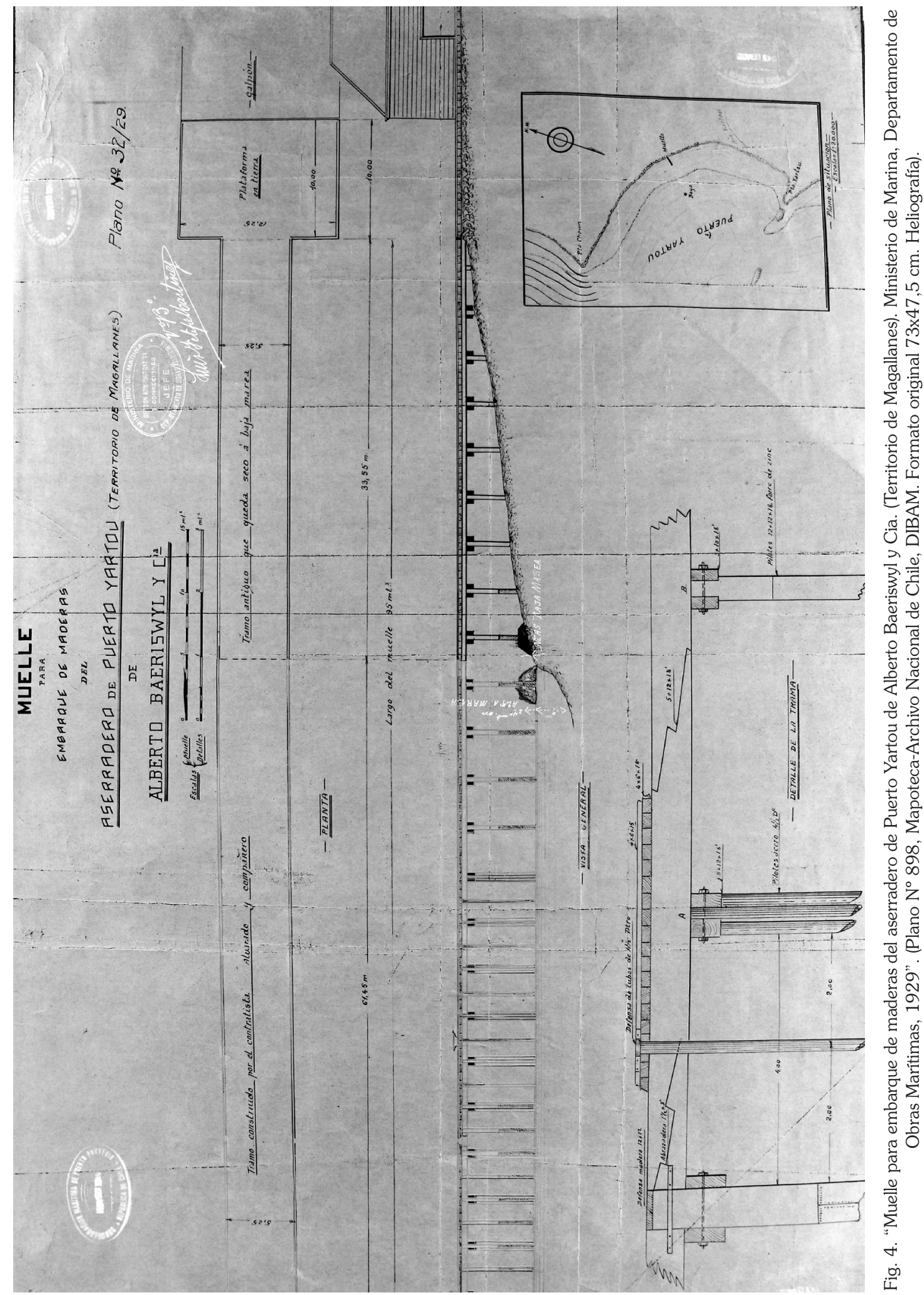




\section{FUENTES DE CONSULTA}

a) Inéditas

- Oficio $N^{\circ} 100$, oficina de la "Propiedad Austral" de Magallanes. Magallanes 6 de febrero de 1931. Agustin Ferrada L. Comunica viaje a Tierra del Fuego.

- Oficio $N^{\circ} 117$, oficina de la "Propiedad Austral" de Magallanes. Magallanes 17 de febrero de 1931. "Alberto Baeriswyl. Sobre entrega 10.000 en Cameron" (Incluye plano de la concesión).

- Oficio No 145, oficina de la "Propiedad Austral" de Magallanes. Magallanes 28 de febrero de 1931. "Pedro Mancilla. Solicita terreno a remate".

- Oficio N 146, oficina de la "Propiedad Austral" de Magallanes.

Magallanes 28 de febrero de 1931. "Diego Ahern. Solicita terreno a remate".

b) Impresas

Fundación Suiza en Puerto Yartou. (2011). Fundación Suiza en Puerto Yartou: Memoria Anual 2010. Santiago: Firma Gráfica.

Fundación Suiza en Puerto Yartou. (2014). Fundación Suiza en Puerto Yartou: Memoria Anual 2013. Santiago: Firma Gráfica.

Martinic, M. (2009 [1982]). La Tierra de los Fuegos. Punta Arenas: Municipalidad de Porvenir.

c) Cartografías

- Parte del Territorio de Magallanes con subdivisión de Tierras. Ministerio de Fomento, Chile, departamento de Tierra y Colonización. 1928. Escala 1:500.000.

- Plano de Tierra del Fuego $N^{\circ} 3$. Decreto Supremo $N^{\circ} 3.686$ del 24 de julio de 1929. Escala 1:250.000.

- Terrenos fiscales a remate en isla Dawson e isla Grande del Depto. De Tierra del Fuego. Escala 1:250.000. Plano hijuelado por Arturo Fernández Correa. Sin año.

- Plano de Tierra del Fuego $N^{\circ}$ 3. Cameron y Almirantazgo. Clasificación y Loteamiento de acuerdo ley $N^{\circ}$ 6.152. Punta Arenas Mayo 1938. Escala 1:250.000.

- Provincia de Magallanes. Subdivisión de Tierras. Ley $N^{\circ}$ 6.152. Punta Arenas, Julio 1941. Escala 1:750.000.

- Plano $N^{\circ}$ 51. Plano de la Provincia de Magallanes. Terrenos de particulares y fiscales con indicación de los loteamientos en conformidad a la ley 6.152. Julio 1955. Escala 1:500.000. 